\title{
Letter to the Editor: An Evidence-Based Algorithm for the Management of Marginal Ulcers following Roux-en-Y Gastric Bypass
}

\author{
Karl Mrak
}

Published online: 9 July 2014

(C) Springer Science+Business Media New York 2014

\author{
Abbreviations \\ MU Marginal Ulcer \\ NSAID Non-steroidal anti-inflammatory drug \\ PPI Proton Pump Inhibitor \\ RYGBP Roux-en-Y Gastric Bypass
}

To the editor:

Obesity surgery recently published an interesting review entitled "An Evidence-Based Algorithm for the Management of Marginal Ulcers following Roux-en-Y Gastric Bypass" by Carr et al. [1]. I absolutely agree with their recommendations concerning the therapeutical management of MU following gastric bypass surgery based on 47 relevant articles including large case series and case control studies. Following their proposed algorithm for the management of MU, patients treated by NSAID and smokers are seen as a high risk group to develop MU and lifelong PPI prophylaxis is recommended. In my opinion, also patients with hyperacidity in their gastric pouch have to be seen as high risk patients and PPI prophylaxis should be performed. Hedberg et al. found that the proximal pouch of patients suffering from MU is significantly more exposed to acid compared to asymptomatic RYGBP patients. In their study, the median percentage of time with $\mathrm{pH}<4$ was $69 \%$ in patients with MU in pH metry and $20 \%$ in asymptomatic RYGBP patients, respectively [2]. Additionally
Siilin et al. found a large amount of acid-producing parietal cells in histologically investigated suture rings of the gastrojejunostomy following stapled anastomosis with circular staplers regardless of the performed pouch size [3].

In my opinion, $\mathrm{pH}$ metry should be included in the presented algorithm of Carr WR for patients suffering from upper gastrointestinal symptoms, additionally to endoscopic investigation. If MU cannot be found as main pathology for upper gastrointestinal symptoms endoscopically, $\mathrm{pH}$ metry should be performed additionally. Except of Helicobacter pylori eradication in these patients lifelong PPI prophylaxis should be administered to patients with detected hyperacidity in their proximal pouch.

Conflict of Interest None.

\section{References}

1. Carr WR, Mahawar KK, Balupuri S, et al. An Evidence-Based Algorithm for the Management of Marginal Ulcers following Rouxen-Y Gastric Bypass. Obes Surg. 2014 May 23. [Epub ahead of print]

2. Hedberg J, Hedenström H, Nilsson S, et al. Role of gastric acid in stomal ulcer after gastric bypass. Obes Surg. 2005;15(10):1375-8.

3. Siilin H, Wanders A, Gustavsson S, et al. The proximal gastric pouch invariably contains acid-producing parietal cells in Roux-en-Y gastric bypass. Obes Surg. 2005;15(6):771-7.

\footnotetext{
K. Mrak

Department of General and Visceral Surgery, Brothers of Mercy Hospital St. Veit/Glan, Teaching Hospital of the Medical University of Graz, St. Veit/Glan, Austria

K. Mrak $(\bowtie)$

Department of Surgery, Brothers of Mercy Hospital, Spitalgasse 26, 9300 St. Veit/Glan, Austria

e-mail:karl.mrak@bbstveit.at
} 